

\section{EXPEDIENTE}

Universidade do Estado do Rio de Janeiro - UERJ

Instituto de Estudos Sociais e Políticos - IESP

\section{CADERNOS DE ESTUDOS SOCIAIS E POLÍTICOS}

www.e-publicacoes.uerj.br/index.php/CESP

\section{COMITÊ EDITORIAL}

Giovana Esther Zucatto, IESP-UERJ

Helio Cannone, IESP-UERJ

Marcelo Borel, IESP-UERJ

Marcia Rangel Candido, IESP-UERJ

Marina Rute Pacheco, IESP-UERJ

Mariane Silva Reghim, IESP-UERJ

Paulo Joaquim Da Silva Rodrigues, IESP-UERJ

Raul Nunes de Oliveira, IESP-UERJ

\section{CAPA, LAYOUT E DIAGRAMAÇÃO}

Marcia Rangel Candido

Raul Nunes de Oliveira

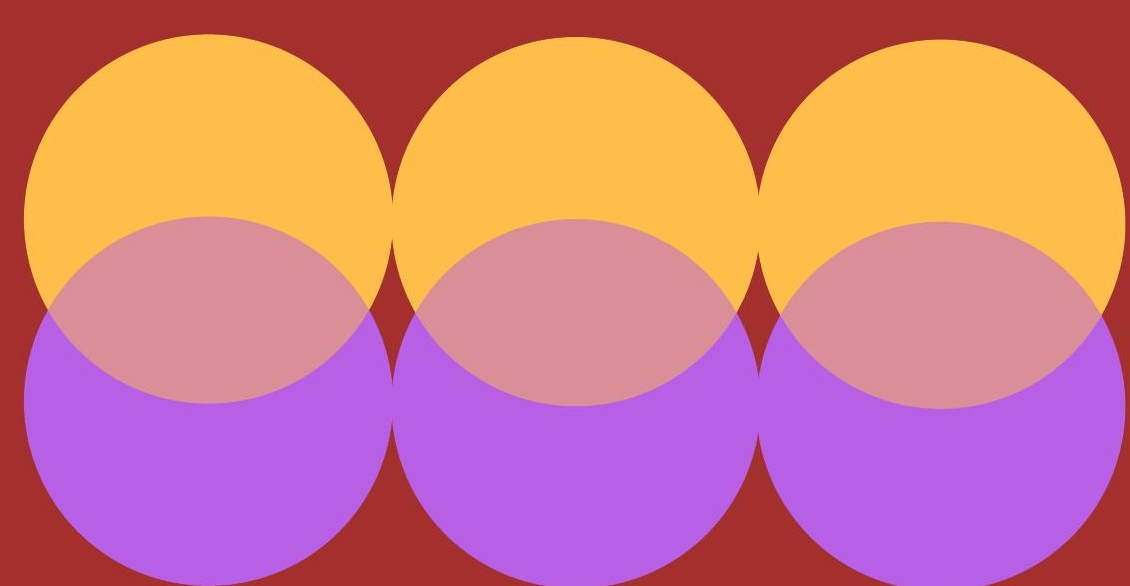


Apresentação

Mariane Silva Reghim e Marcelo Borel

Dossiê

As Expressões Do Racismo Institucional Nas Universidades Federais Do

Estado Do Rio De Janeiro: Mulheres Negras Trabalhadoras e Intelectuais

Cibele da Silva Henriques

Ressignificando As Raças: Os Deuses Pretos e Os Demônios Brancos No Discurso Nacionalista Preto Da Nação Do Islã nos Estados Unidos Da América

Rafael Filter Santos da Silva

Feminismo Negro e a Interseccionalidade de Gênero, Raça e Classe

Eunice Lea de Moraes Lucia Isabel Conceição da Silva

A Corporeidade e a Liberdade: Mulheres Negras e a Coragem De Ser

Joyce Gonçalves Restier da Costa Souza

\section{Artigos}

Os Governos Do PT e As Agências De Rating: Os Percalços De Treze Anos De Relação

Pedro Lange Netto Machado

Apropriação Cultural: Novas Configurações das Identidades na Era da Globalização

Bárbara Lopes Heleno e Rafaella Max Reinhardt

Resenha Crítica: O Segredo como Conceito Político: a propósito de Democracia e Segredo de Norberto Bobbio

Ronaldo Tadeu de Souza 


\title{
As Expressões Do Racismo Institucional Nas Universidades Federais Do Estado Do Rio De Janeiro: Mulheres Negras Trabalhadoras e Intelectuais
}

\author{
The expressions of institutional racism in the federal universities of the state of Rio de Janeiro: black female \\ workers and intellectuals.
}

Cibele da Silva Henriques ${ }^{1}$

\begin{abstract}
RESUMO
O presente artigo é fruto de reflexões sobre o objeto de pesquisa da tese de doutorado que consiste na análise das expressões do racismo institucional no cotidiano profissional das assistentes sociais das universidades federais do Estado do Rio de Janeiro, as quais têm promovido lutas pelo direito ao trabalho sem caráter doméstico, sem discriminações de classe, gênero, raça e etnia. Enfim, a obtenção de recursos que as instrumentalizem na luta contra o racismo institucional, tão funcional ao sistema capitalista e estrutural nas relações sociais na sociedade brasileira
\end{abstract}

PALAVRAS-CHAVE: Mulheres Negras; Trabalho; Racismo Institucional

\begin{abstract}
:
This article is the result of reflections on the research object of the doctoral thesis that consists of the analysis of the expressions of institutional racism in the professional daily life of the social workers of the federal universities of the State of Rio de Janeiro, which have promoted struggles for the right to work without domestic character, without discrimination of class, gender, race and ethnicity. Finally, the obtaining of resources that instrumentalize them in the fight against institutional racism, so functional to the capitalist and structural system in social relations in Brazilian society
\end{abstract}

KEYWORDS: Black Women; Job; Institutional Racism

1 Doutoranda no Programa de pós-graduação da Escola de Serviço Social da UFRJ, Assistente Social do Instituto de Psiquiatria da UFRJ (IPUB-UFRJ) e Docente da Universidade Castelo Branco. Email: cibhenriques@gmail.com 


\section{INTRODUÇÃO}

O processo de hierarquização das relações sociais entre homens e mulheres de diversas raças e etnias não é exclusivo do sistema capitalista, houve experiências precedentes no período feudal $^{2}$, mas sem dúvida, tal processo de organização do trabalho coletivo ganhou maior capilaridade no modo de produção capitalista, no qual o trabalho passou a ser concebido a partir de uma nova determinação social - a expropriação - fundante no processo da chamada "acumulação primitiva”, que se deu por meio da expropriação da terra, dos meios de produção, do produto final do trabalho coletivo, do corpo das mulheres, dos saberes milenares das curandeiras e bruxas, em contraposição à crescente apropriação dos bens socialmente produzidos por uma minoria de homens brancos, europeus e católicos que representavam a nascente burguesia mercantil (FEDERICI, 2017).

Marx (2004) destaca que essa dicotomia no que tange à apropriação da terra, capital e renda arregimentou o processo de assalariamento e a formação de duas classes: a classe de proprietários (provida dos meios de produção) e a classe de trabalhadores (desprovida de propriedade e riqueza). No entanto, não aponta a distinção de raça e gênero que perpassou o processo de expropriação dos trabalhadores e fixou as mulheres na divisão social do trabalho como meras responsáveis do processo de reprodução social dos trabalhadores, que inclui, a produção em larga escala de força de trabalho para o capital.

É a partir desse pressuposto das "expropriações permanentes" inerente ao modo de produção capitalista, as quais estão submetidas às mulheres negras trabalhadoras no Brasil desde a escravidão até os dias atuais, que desenvolveremos nossa análise sobre os "racismos e sexismos" que incidem no cotidiano profissional das mulheres negras trabalhadoras que atuam no serviço público federal, em especial, no itinerário profissional das assistentes sociais negras trabalhadoras que conjugam duplamente o ethos do "servir".

A escolha das assistentes sociais negras trabalhadoras como público-alvo da presente pesquisa não foi aleatória, mas sim para contrapor o mito de "os racismos e os sexismos" não

$2 \quad$ Ver FEDERICI (2017). 
incidem no cotidiano profissional das mulheres negras com um alto grau de instrução, bem como não são alvos de resistência por parte dessas mulheres no serviço público federal.

Para além, a presente pesquisa visa à sistematização de dados sobre a inserção das mulheres no serviço público federal, bem como comparar tais dados gerais com a inserção da mulher negra no mercado de trabalho, com vistas a construir um estudo comparativo, haja vista que se avoluma o quantitativo das mulheres negras trabalhadoras no serviço público federal, quer seja pela adoção de cotas étnico-raciais na educação e no serviço público federal.

No que tange à categoria racismo utilizaremos a conceituação utilizada por Silvio Almeida (2016), contida no dossiê marxista sobre raça, o qual concebe o "Racismo como uma relação social, que se estrutura política e economicamente”. Não obstante, também problematizaremos a expropriação da categoria raça do processo de construção da categoria "questão social" no Brasil. Consideramos que tal "expropriação conceitual" dificulta a percepção do racismo como uma relação social e econômica, que é funcional ao modo de produção capitalista, que produz "expropriações permanentes".

Ademais, para explicitar "os racismos", as quais estão submetidas às mulheres negras trabalhadoras no Brasil, faremos um resgate histórico do processo de constituição do racismo institucional no Brasil que se imbrica com a gênese dos serviços públicos no Brasil, que se forjaram a partir do recrutamento das mulheres negras libertas para a realização de atividades braçais em Hospitais, Hospícios, Casas de Correção, Santas Casas, Fábricas de Ferro e nas Obras públicas (BERTIN, 2006, p. 50).

Portanto, compreendemos que no Brasil a iconografia das mulheres negras trabalhadoras é constituída pela representação do "servir" desde a escravidão até os dias atuais, a qual está na gênese dos serviços públicos, que se constituiu como lócus fundante para a perpetuação do racismo institucional.

Mediante o exposto, tecemos como hipótese central do presente estudo que - a "expropriação servil" que consubstancia a imagem e auto-imagem das mulheres trabalhadoras negras no Brasil desde a escravidão até os dias atuais, fruto no processo de colonização sexista, racista e heteropatriarcal que incutiu que as mulheres afro-descendentes deveriam "servir" aos colonizadores, bem como colaborar com o desenvolvimento do capitalismo a partir das 'expropriações permanentes, potencializa 'os racismos' que estão na raiz da formação sócio-brasileira, em especial, o racismo institucional que se imbrica e interconecta com a constituição dos serviços públicos no Brasil”. 
Esta indagação, ainda sem respostas, nos motiva a ensaiar o itinerário dessa pesquisa que tem como eixos norteadores: o resgate sócio-histórico do processo de inserção das mulheres negras trabalhadoras "libertas" no mercado de trabalho no Brasil, em especial, nos serviços públicos; o resgate da gênese das protoformas do racismo institucional no Brasil; a identificação dos "racismos" existentes no serviço público federal, que incidem no cotidiano profissional das mulheres negras trabalhadoras; Reconhecer as formas de perpetuação do racismo institucional para as mulheres negras trabalhadoras que possuem nível superior, em especial àquelas que desempenham funções ligadas ao cuidado, como por exemplos as/os assistentes sociais; difundir as formas de enfrentamento possíveis do racismo institucional no serviço público federal.

No que tange à relevância da pesquisa, reiteramos que a presente pesquisa é de suma importância porque ainda, as mulheres negras trabalhadoras no Brasil que ousaram romper com o ethos do "servir" sofrem cotidianamente com o racismo estrutural e institucional que está no cerne das relações sociais no Brasil, as quais são estruturadas por desigualdades de classe, gênero, raça e etnia.

Se analisarmos como se gesta no mercado de trabalho essas relações sociais de classe, gênero e raça verificamos que de acordo com os dados divulgados pelo Instituto Brasileiro de Geografia e Estatística (IBGE), sobre o período referente ao quarto trimestre de 2016, as mulheres negras e pardas ganham menos de dois salários-mínimos, em contraposição às mulheres brancas, cujo valor remuneratório é de cerca de dois salários-mínimos e meio, enquanto os homens brancos ganham cerca de três salários-mínimos. (IBGE, 2016).

Contudo, não é somente a diferença salarial que exprime as hierarquizações de classe, gênero e raça no Brasil, mas também as situações de racismo institucional e injúria social que incidem no cotidiano profissional dos trabalhadores negros. Recentemente, a modelo Nérida Cocamaro, 25 anos, nascida em Guiné-Bissau, na África relatou numa reportagem a uma emissora de TV que "Ninguém nunca fala explicitamente: 'a gente não quer trabalhar com você por conta da cor da sua pele', mas eu percebo que o tratamento comigo é diferente pelo meu tom de pele. São coisa que a gente tem que quebrar todos os dias" (GLOBO, 2017).

Desse modo, se faz urgente a identificação dos racismos que acometem as mulheres negras trabalhadoras no Brasil, que acontecem diariamente no cotidiano profissional, bem como reconhecer as formas de enfrentamento, haja vista que nem sempre as situações de racismo e de “injúria racial” são percebidas pelas mulheres e, por conseguinte denunciadas. E ainda, quando 
são denunciadas as situações de "racismo e de injúria racial" se travestem em casos de "assédio moral", o que esvazia o teor racial da denúncia.

Cabe frisar que as situações de Racismo são aquelas que incidem sobre a coletividade, ou seja, geram preconceitos e discriminações que atingem a raça, enquanto, a injúria racial consiste na ofensa à honra de uma determinada pessoa, valendo-se de elementos referentes à raça, cor, etnia, religião ou origem. Contudo, compreendemos que ambas as situações expressam as desigualdades de gênero, raça e etnia que estruturam as relações sociais no Brasil.

No que concerne à metodologia adotada, utilizaremos a pesquisa militante que permite a valorização das vozes dos sujeitos participantes - as mulheres negras trabalhadoras - bem como nos possibilita divulgar as suas estratégias de enfrentamento ao racismo institucional. Em relação à coleta de dados, vamos utilizar questionários com uma estrutura mais flexível para que as mulheres negras trabalhadoras possam narrar sua trajetória profissional e os seus processos de resistência às opressões de gênero e raça (GOHN, 1987).

Para além, a relevância do presente estudo se renova na medida em que há poucos estudos sobre o racismo e o sexismo no serviço público federal brasileiro que incidem no cotidiano profissional das mulheres negras trabalhadoras, como nos mostra o quadro a seguir, no qual fizemos uma breve revisão bibliográfica sobre os artigos que abordam a temática racial, inclusive, de modo transversal pela feminização do cuidado e a produção de cuidado no âmbito da saúde.

\section{Quadro 1 - Tema: Racismo Institucional - Subtema: Artigos que abordam a temática do racismo institucional. Total de 8 artigos.}

\begin{tabular}{|c|c|c|c|c|}
\hline Tema & Título & Revista & Ano & Autor/Autora \\
\hline $\begin{array}{c}\text { Racismo Institucional } \\
\text { e saúde da população } \\
\text { negra }\end{array}$ & $\begin{array}{c}\text { Racismo institucional e Saúde } \\
\text { da população negra }\end{array}$ & Saúde e Sociedade & 2016 & Jurema Werneck \\
\hline $\begin{array}{c}\text { Racismo } \\
\text { Intitucional e saúde } \\
\text { mental }\end{array}$ & $\begin{array}{c}\text { "De escravas à cuidadoras: a } \\
\text { invisibilidade das mulheres } \\
\text { negras na política de saúde } \\
\text { mental }\end{array}$ & O social em questão & 2017 & $\begin{array}{c}\text { Raquel } \\
\text { Gouveia }\end{array}$ \\
\hline $\begin{array}{c}\text { Racismo Institucional } \\
\text { e saúde }\end{array}$ & $\begin{array}{c}\text { O conceito de racismo } \\
\text { institucional: aplicações no } \\
\text { campo da saúde }\end{array}$ & $\begin{array}{c}\text { Interface entre } \\
\text { comunicação, saúde e } \\
\text { educação }\end{array}$ & 2012 & Laura Cecília López \\
\hline $\begin{array}{c}\text { Racismo Institucional } \\
\text { institucional: a psicologia na } \\
\text { produção científica nacional. }\end{array}$ & $\begin{array}{c}\text { Revista do Conselho } \\
\text { Regional de } \\
\text { Psicologia }\end{array}$ & 2010 & $\begin{array}{c}\text { Antonio Richard } \\
\text { Carias; Rômulo } \\
\text { Lopes da Silva }\end{array}$ \\
\hline Racismo Institucional & Eichmann, o Racismo & Revista Gestão \& & 2013 & Gislene Aparecida \\
\hline
\end{tabular}




\begin{tabular}{|c|c|c|c|c|}
\hline & $\begin{array}{c}\text { Institucional e as Políticas } \\
\text { Públicas: reflexões sobre o } \\
\text { PIMESP e outras políticas }\end{array}$ & Políticas Públicas & dos Santos \\
\hline $\begin{array}{c}\text { Racismo Institucional } \\
\text { e Formação em } \\
\text { Educação }\end{array}$ & $\begin{array}{c}\text { Racismo Institucional: pontos } \\
\text { para reflexão }\end{array}$ & $\begin{array}{c}\text { Laplage em Revista: } \\
\text { Revista do programa } \\
\text { de educação da } \\
\text { UFSCAR }\end{array}$ & 2017 & $\begin{array}{c}\text { Marcos Antonio Batista } \\
\text { da Silva }\end{array}$ \\
\hline $\begin{array}{c}\text { Racismo Institucional } \\
\text { e Políticas Públicas }\end{array}$ & $\begin{array}{c}\text { Assistência Social, no enlace } \\
\text { entre a cor e gênero dos (as) } \\
\text { que dela necessitam }\end{array}$ & O Social em Questão & 2017 & Gracyelle Costa \\
\hline $\begin{array}{c}\text { Racismo Institucional } \\
\text { e Formação em } \\
\text { Serviço Social }\end{array}$ & $\begin{array}{c}\text { A Questão Étnico-racial no } \\
\text { Processo de Formação em } \\
\text { Serviço Social }\end{array}$ & $\begin{array}{c}\text { Revista Serviço Social } \\
\text { e Sociedade }\end{array}$ & 2009 & $\begin{array}{c}\text { Roseli da Fonseca } \\
\text { Rocha }\end{array}$ \\
\hline
\end{tabular}

Total: 8 artigos. Fonte: www.scielo.org. Acesso em 29/10/2017.

Essa breve pesquisa não esgota a produção de artigos sobre o tema do Racismo Institucional, mas sem dúvida, nos mostra um panorama da produção acadêmica sobre o tema, bem como algumas lacunas na confecção de pesquisas, como, por exemplo, sobre o Racismo Institucional no Serviço Público Federal, especificamente sobre sua repercussão no cotidiano profissional das mulheres negras trabalhadoras que possuem nível superior.

Não obstante, em recente pesquisa realizada pela Associação dos Docentes da UFRJ (AdUFRJ), cuja fonte de coleta de dados foi o Censo da Educação Superior (2013-2016), constatou-se que apenas $2 \%$ dos docentes da UFRJ se declaram negros, um percentual menor do que a média das universidades federais, estaduais e particulares, como mostra os gráficos 2 e 3 , abaixo.

Gráfico 2

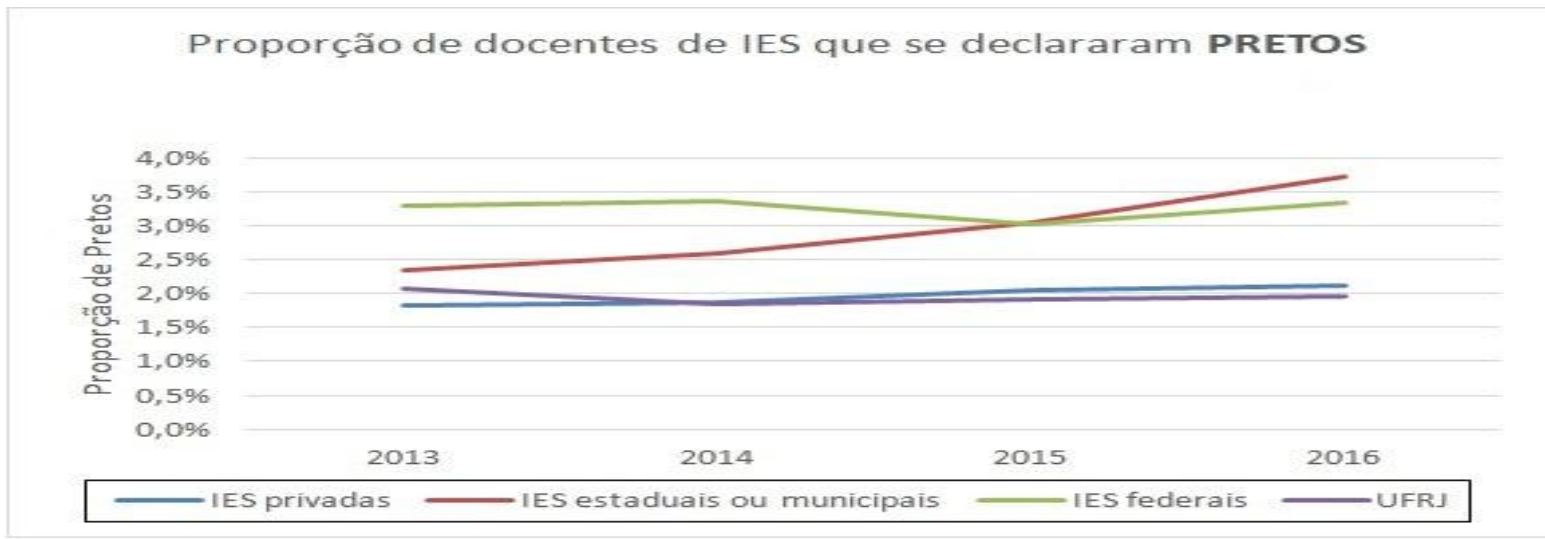

Fonte: Censo do Ensino Superior, segundo categorias administrativas e UFRJ - Brasil, 2013 a 2016. In: http://www.adufrj.org.br/. Acesso em 18/11/2107. 
Gráfico 3

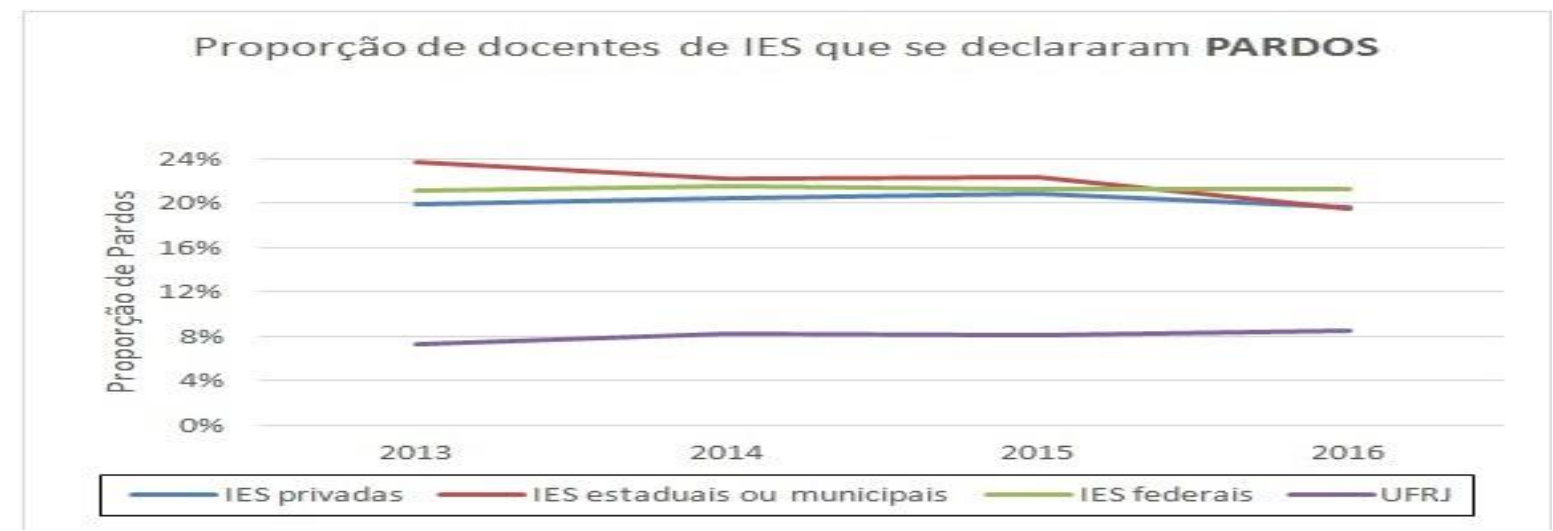

Fonte: Censo do Ensino Superior, segundo categorias administrativas e UFRJ - Brasil, 2013 a 2016. In: http://www.adufrj.org.br/. Acesso em 18/11/2107.

Em contraponto, o percentual de docentes da UFRJ que se declaram pardos é de 8\%, um número significativo que expressa que ainda os intelectuais no Brasil tem a percepção da cor/raça baseada em critérios adotados pelo sistema classificatório do Instituto Brasileiro de Geografia e estatística (IBGE) que define "Raça e cor" a partir de cinco categorias: branca, preta, parda, amarela e indígena, pois tal classificação não permite a análise das desigualdades raciais.

De acordo com a pesquisa realizada pelo Instituto de Pesquisa Econômica Aplicada (IPEA) sobre “O sistema classificatório de 'Raça e cor' do IBGE” (2003), é inadequado, ao menos, para fins de pesquisa e caracterização das desigualdades raciais existentes no Brasil o uso da identificação racial por meio do uso simultâneo de "auto-atribuição e de heteroatribuição de pertença”. Contudo, frisam que no Brasil as pessoas têm a liberdade de declarar sua cor e raça e utilizam o sistema classificatório do IBGE, sem ao menos problematizar se, de fato, tal classificação, que introduz a categoria "parda e preta" em vez de "negra", lhes representa realmente ou se contribui para mascarar as desigualdades sociais, econômicas e raciais existentes entre negros e brancos no Brasil (Ibidem, 2013, p. 7).

Nesse sentido, consideramos que a presente pesquisa além de nos possibilitar o reconhecimento dos racismos existentes no serviço público federal, pode também nos possibilitar outras chaves analíticas no que concerne às desigualdades raciais nas instituições públicas, que incide nas diversas carreiras profissionais, independente do grau de instrução/qualificação profissional. 


\section{MULHERES NEGRAS TRABALHADORAS \& INTELECTUAIS NAS UNIVERSIDADES FEDERAIS DO ESTADO DO RIO DE JANEIRO: INVISIBILIDADE E RACISMO}

A retórica de que as mulheres Afro-latino-americanas e Afro-caribenhas devem desempenhar as atividades domésticas, em detrimento das atividades intelectuais tem sua raiz no processo de colonização sexista, racista e heteropatriarcal, o qual incutiu que as mulheres não brancas deveriam "servir" aos colonizadores, bem como colaborar com o desenvolvimento do capitalismo, a partir da extração permanente de lucros por meio do trabalho não-pago, de preferência no âmbito doméstico e dos serviços é uma falácia.

\footnotetext{
A socialização sexista inicial que ensina as negras e na verdade a maioria das mulheres que o trabalho mental tem de ser sempre secundária aos afazeres domésticas ao cuidado dos filhos ou a um monte de outras atividades servis tornou difícil para elas fazer do trabalho intelectual uma prioridade essencial mesmo quando suas circunstâncias sociais ofereciam de fato recompensas por essa atividade (hooks, 1995, p.471).
}

No Brasil, a colonização também teve um teor racista, sexista e heteropatriarcal. A historiadora Bertin (2006) aponta que os dirigentes paulistas, no período de 1851-1889, para se desonerarem do custo da mão de obra utilizada nos serviços públicos, como por exemplo, o custo das férias e dos aluguéis de moradia exigido pelos imigrantes europeus e alemãs, então se utilizaram dos africanos livres, homens e mulheres, nos serviços públicos, a saber: Obras Públicas (92), Casas de Correção (15), Hospícios (05), Jardim Público (10), Quartel do Campo Fixo (06), Santa Casa (03), Seminário das Educandas(10), Seminário de Santana (04), Tesouraria (01) e Fábrica de Ferro (95) (Ibidem, 2006, p. 50).

Tal cenário de cordialidade racial e benevolência propalada pelos dirigentes brasileiros através do "discurso mitológico da democracia racial" e por meio da instilação de "serviços sociais públicos" não promoveu a melhora das condições de vida e trabalho da população negra no Brasil, principalmente, das mulheres negras trabalhadoras que sempre tiveram que sustentar a família por meio de trabalhos aviltantes quer seja no âmbito doméstico, quer seja no setor de serviços (cf. as argumentações de FERNANDES, 1989; BARBOSA GOMES, 1999; HERINGER, 2002; PAIXÃO, 2006). 
A partir dessa pesquisa realizada por Bertin (2006), consideramos que as protorformas do racismo institucional $^{3}$ no Brasil se imbricam e se interconectam com a organização dos serviços públicos no país, que é anterior aos idos de 1930-1945, período em que há o processo de reconhecimento da "questão social" por parte do Estado com a institucionalização dos serviços sociais públicos e sua ampliação, mas também a dicotomização da questão racial e social, já que o Estado não reconheceu que a questão racial é basilar e emoldura a questão social no Brasil.

No que tange as mulheres negras trabalhadoras, nosso foco de análise, as estatísticas revelam que as condições de vida e trabalho das mulheres negras ainda são precárias, segundo a Pesquisa Nacional de Domicílios (PNAD/IBGE, 2015) as mulheres negras representam 25\% do contingente feminino da população brasileira, possuem uma expectativa cinco vezes menor do que a das mulheres brancas, ocupam postos de trabalho com vínculos empregatícios precários, cerca de 60\% do contingente de mulheres negras desempenham atividades domésticas remuneradas. Ademais, segundo o Mapa da Violência de 2010, são as mulheres negras que mais morrem vítimas de feminicídio no Brasil.

Mediante tais disparidades, os Movimentos feministas negros têm lutado por leis que assegurem o ingresso e a permanência da população negra na educação superior pública e no serviço público federal, por meio da adoção de cotas, respectivamente $50 \%$ nas universidades federais e 20\% das vagas de concursos públicos da Administração Pública Federal.

Diferentemente da implementação das cotas raciais na educação superior que já alcança um contingente de 50\% do das vagas desde 2016, a adoção de cotas no serviço público federal tem sido implementada aos poucos pelos órgãos públicos, ou seja, à conta-gotas, quer seja pela juventude da lei, quer seja pela retração de concursos na área federal desde 2014, como mostra o quadro abaixo, referente às universidades públicas do Estado do Rio de Janeiro:

\section{Quadro 1 - Tema: Lei 12.990/2014 - Subtema: Lei sobre reserva de 20\% de vagas para negros oferecidas para provimento de cargos efetivos e empregos públicos para técnico- administrativos no âmbito da administração pública federal, nas universidades federais do Estado do Rio de Janeiro.}

\footnotetext{
3 Nesse estudo entendido como "qualquer sistema de desigualdade que se baseia em raça que pode ocorrer em instituições como órgãos públicos governamentais, corporações empresariais privadas e universidades (públicas e privadas)" (Wikipédia, 2017, grifos meus).
} 


\begin{tabular}{|l|l|l|l|l|}
\hline \multicolumn{1}{|c|}{ Ano } & Instituição & Edital/ano & $\begin{array}{c}\text { Total de vagas para } \\
\text { assistentes sociais } \\
\text { (nível superior) }\end{array}$ & $\begin{array}{c}\text { Total de vagas para } \\
\text { assistentes sociais } \\
\text { negros (nível superior) }\end{array}$ \\
\hline 2013 & UNIRIO & $002 / 2013$ & 2 & 0 \\
\hline 2013 & UFRRJ & $124 / 2013$ & 1 & 0 \\
\hline 2014 & UFRJ & $70 / 2014$ & 8 & 0 \\
\hline 2017 & UFRJ & $445 / 2017$ & 4 & 0 \\
\hline
\end{tabular}

Total: 4 editais. Fonte: http://www.planejamento.gov.br/. Elaboração Própria. Acesso em 07/08/2017

Apesar da conjuntura desfavorável, do pós-golpe do mandato presidencial de Dilma Rousseff, na qual o presidente interino Michel Temer vem realizando cortes de verbas significativos do orçamento das Instituições federais, inclusive no que toca a concursos e provimento de vagas, é perceptível que mesmo após a promulgação da Lei de cotas no serviço público federal, os editais apontam um deficit de vagas para negros e negras, como verificamos no edital 445/2017 da UFRJ não há reserva de vagas para negros no Serviço Social, uma profissão majoritariamente negra e parda.

Não obstante, em relação ao edital 445/2017 num total de 61 vagas de nível superior somente se tem 04 reservadas vagas para negros e negras. Já em relação às vagas para nível médio/médio técnico e fundamental têm-se um total de 106 vagas, temos a reserva de 19 vagas. Assim sendo, percebemos que mesmo após a Lei 12.990/2014, ainda são reservados para os negros e as negras as funções de provimento com menor escolaridade/qualificação profissional no serviço federal. Essa observação está relacionada com o número de vagas em cada edital.

Desse modo, no Brasil o racismo institucional se imbrica com a organização dos serviços públicos, cumpre uma funcionalidade na sociedade heteropatriarcal, racista e sexista de manter uma pretensa cordialidade entre as "classes sociais racializadas e assexuadas", bem como manter as mulheres negras trabalhadoras em posições fixas no mercado de trabalho, o que contribui para a perpetuação da iconografia do "servir", principalmente entre assistentes sociais - profissionais com nível superior cuja imagem social é "servir aos necessitados".

Nesse sentido, compreendemos que a institucionalização e a implementação de ações afirmativas, como meras semelhanças nas áreas de direito da mulher e igualdade racial, não minorou as desigualdades de raça/etnia e gênero nas instituições públicas, em especial, nas universidades federais.

$\mathrm{Na}$ breve pesquisa empírica que realizamos para a coleta de dados, que se deu por meio de enquete num dispositivo de mensagem virtual, em julho de 2017, com as assistentes sociais da 
UFRJ (54 mulheres), que atuam em diversas áreas: saúde, educação, assistência estudantil, algumas participantes falaram que conhecem casos de colegas que sofreram "assédio moral com viés racista".Ao indagarmos "o que seria essa modalidade de assédio?" Não sabem explicar, mas dizem que as vítimas desconfiam que os obstáculos que sofrem para a progressão na carreira em alguns setores é porque são negras e pardas, pois vivem mudando de setor e sempre são acometidas pelos mesmos problemas: uma cobrança maior de produtividade; cobranças diferenciadas em termos de resultados e um controle rígido das chefias, o que não ocorre com funcionários mais antigos e que não são negros ou pardos.

Ao refletimos sobre tais dados preliminares, percebemos que os servidores nomeiam "racismo institucional" como "assédio moral com viés racista", o que despolitiza o conceito de racismo, que deixa de ser uma discriminação étnico-racial de base institucional para ser um problema não institucional, de ordem pessoal, relacional que deve ser mediado pela equipe funcional da saúde do trabalhador, pois se trata de um caso de "não adequação comportamental" que pode ter influências fisiológicas ou subjetivas.

Enfim, consideramos que na medida em que não há o reconhecimento da comunidade acadêmica de que o racismo institucional não é assédio moral, mas sim uma desigualdade de raça/etnia e de gênero que está na gênese da constituição dos serviços públicos, não conseguiremos avançar nessa discussão nas universidades federais, ainda eurocêntricas, sexistas, racistas e heteropatriarcais, vide que ainda menosprezam e obstaculizam a produção intelectual de mulheres negras com formação em nível superior.

hooks (1995) aponta que quando publicou a sua coletânea de ensaios "Talking Back" (Retrucando) se surpreendeu com as muitas cartas que recebeu de negras discutindo o ensaio sobre as dificuldades de desenvolver um trabalho intelectual, então pode perceber como as mulheres negras trabalhadoras e intelectuais são ainda invisíveis, como cita abaixo:

\footnotetext{
As intelectuais negras que não são escritoras famosas (e nem todos os escritores são intelectuais) continuam praticamente invisíveis nessa sociedade Essa invisibilidade e ao mesmo tempo em função do racismo do sexismo e da exploração de classe institucionalizados e um reflexo da realidade de que grande número de negras não escolhem o trabalho intelectual como sua vocação (hooks, 1995, p. 4).
}

Para hooks (1995) o intelectual não é apenas alguém que lida com ideias, mas sim aqueles que lidam com as ideias transgredindo fronteiras discursivas e as interrelaciona com a cultura 
política mais ampla. No entanto, ao falar de sua autobiografia relata que como esse processo de ruptura com o instituído é perpassado pelo racismo e sexismo, enraizado nas instituições sociais.

\begin{abstract}
[...] enfrentei como estudante universitária perseguição de professores pares e colegas profissionais A norma geral eram relatos sobre negras sendo interrogadas pelos que procuravam determinar se ela era capaz de concluir o trabalho pensar logicamente escrever coerentemente Essas formas de importunação muitas vezes solapam a capacidade das negras de transmitir a certeza de talento e domino intelectual Depois havia as histórias - contadas através de cartas - de depressão e desespero que ameaçavam a própria vida No todo essas cartas confirmam que a opção de seguir uma carreira acadêmica e/ou intelectual da maneira socialmente legítima continua a ser uma árdua tarefa para negras Embora hoje mais que nunca haja, sem dúvida, muito mais negras acadêmicas elas são na maioria das vezes anti-intelectuais (uma posição que e frequentemente consequência do sofrimento que suportaram como alunas ou professoras encaradas com desconfiança e desprezo por seus pares) $\mathrm{Na}$ vida diária podem insistir em que o trabalho que fala diretamente a experiência concreta e mais valioso que as formas de trabalho intelectual não produzidas para ser comercializadas para um público de massa Diante da falta de endosso e apoio públicos constantes as negras que escolhem vocações intelectuais quando enfrentam esse trabalho em isolamento em espaços privados não admira que negras individualmente se sintam oprimidas por dúvidas que esses espaços intensifiquem receios de incompetência receios de que suas ideias talvez não mereçam ser ouvidas. (hooks, 1995, p. 472)
\end{abstract}

No Brasil, as mulheres trabalhadoras negras que ousam transpor as desigualdades de raça através dos recursos intelectuais também se deparam constantemente com os obstáculos advindos do sexismo e racismo institucional que invisibiliza o itinerário acadêmico dessas mulheres desde a formação universitária até a inserção no mercado de trabalho, as silencia e as subalterniza.

\title{
CONSIDERAÇÕES FINAIS
}

Safiotti (2004) aponta que o patriarcado consiste num esquema de dominação-exploração, o qual é transversal a toda sociedade e que incide sobre homens e mulheres na sociedade capitalista por meio das relações sociais, ou melhor, por meio das relações de poder, na qual o feminino é tido como "ser genérico", "abstrato" e "invisível”.

Mediante isso, a autora supracitada salienta que devemos estudar as "mulheres na sociedade de classes" a partir da ótica da indissociabilidade do gênero, raça e patriarcado. A partir de tal pressuposto compreendemos que inscrever essa tríade "patriarcado-gênero-raça" no campo 
das relações de poder pode ser um analisador potente para desvelar as situações de racismo e sexismo pelas quais as mulheres negras trabalhadoras passam na sociedade de classes, em especial as mulheres negras trabalhadoras do serviço público federal que ousam romper com o invólucro da servidão doméstica compulsória para a imersão na intelectualidade.

Desse modo, se faz indispensável as lutas empreendidas pelas feministas negras no Brasil contra as desigualdades de raça e pela igualdade racial, as quais têm promovido "práticas sociais transgressoras", no sentido de minorar a sujeição das mulheres negras ao trabalho servil por meio da qualificação profissional, porém a instilação das ações afirmativas no âmbito jurídico-legal não têm afiançado de fato a mudança do "status quo" do contrato social, ou melhor, "contrato sexual" nos termos de Parteman (1993) que produz liberdades para os homens e a sujeição para mulheres, sujeições estas hierarquizadas pela raça e gênero (hooks, 1995; PATERMAN, 1993).

Assim sendo, concluímos que para além das ações afirmativas os movimentos feministas negros precisam promover "rupturas" nesse processo de dominação-exploração que assujeita as mulheres negras trabalhadoras ao servilismo, o qual é tão funcional ao sistema capitalista, bem como se faz urgente criar mecanismos de denúncia das situações deracismo institucional, o qual cordializa os corpos negros para o processo de "superexploração" do capital.

Submetido para avaliação em 28 de março de 2018 Aprovado para publicação em 12 de junbo de 2018

\section{BIBLIOGRAFIA}

ARAÚJO, Renato (2015). Apostila para os Educadores da Expo. “Zumbi: a guerra do povo negro". Editora SESC. Acessado em 26/09/2018 e disponível em: http://museuafrobrasil.org.br/docs/default-source/publica $\% \mathrm{C} 3 \% \mathrm{~A} 7 \% \mathrm{C} 3 \% \mathrm{~B} 5 \mathrm{es} /$-nbsparquivo-em-pdf.pdf?sfvrsn.

BARBOSA, Alexandre de Freitas (1999). A formação do mercado de trabalho no Brasil. São Paulo: Alameda.

BERTIN, Edenilce (2006). Os meia-cara: africanos livres em São Paulo no século XIX. Tese de Doutorado. São Paulo, FFLCH-USP. 
CARVALHO, José Murilo de (2008). Cidadania no Brasil: o Longo caminho. 11. ed., Rio de Janeiro: Civilização Brasileira.

CHAUÍ, Marilena (2014). Brasil: Mito fundador e sociedade autoritária. In: CHAUÍ, Marilena \& Rocha, André (Orgs). Manifestações ideológicas do autoritarismo brasileiro. Belo Horizonte: Autêntica; Editora Fundação Perseu Abramo.

FEDERICI, Silvia (2017). O Calibã e a Bruxa: mulheres, corpo e acumulação produtiva. São Paulo, Elefante Editora.

FERNANDES, F (1989). O negro no mundo dos Brancos. 2. ed. ver. São Paulo: Global.

HERINGER, R (2002). Desigualdades raciais no Brasil: Síntese de indicadores e desafios no campo das políticas públicas. Caderno de Saúde Pública, Rio de Janeiro, n.18, p. 57-68.

hooks, bell. Intelectuais Negras (1995). ESTUDOS FEMINISTAS, UFSC, 477 n.2. Acessado em 26/09/2018.e disponível em: https://periodicos.ufsc.br/index.php/ref/article/view/16465

INSTITO DE PESQUISAS ECONÔMICAS APLICADAS - IPEA (2013). Dossiê mulheres negras: retrato das condições de vida das mulheres negras no Brasil. Marcondes, Mariana M. [et al.].- Brasília: IPEA. Acessado em 26/09/2018 e disponível em: www.ipea.gov.br.

INSTITUTO BRASILEIRO DE GEOGRAFIA E ESTATÍSTICA - IBGE (1996). Pesquisa Mensal de Trabalho, ano 1996. Rio de janeiro: IBGE. Acesso em 26/09/2018 e disponível em: <http: www.ibge.gov.br/home/estatistica/populacao/mapa mercado trabalho/default.shtm>

Pesquisa mensal de Emprego 2006. Rio de Janeiro: IBGE. Disponível em: $<$ http://www.ibge.gov.br/home/estatistica/populacao/mapa mercado trabalho/default.shtm> Acessado em 26/09/2018.

Pesquisa Nacional por Amostra de Domicílios (PNAD), 2015 apud Revista Exame, 2015. Disponível em: http://exame.abril.com.br/economia/noticias/empregodomestico-volta-a-crescer-no-brasil-mostra-ibge. Acesso em 19/01/2017.

LUGONES, M. (2015). Colonialidad e género. In: MUÑOZ, K. CORREAL, D. e MIÑOSO, Y. Tejiendo de outro modo: Feminismo, epistemologia y apostas descoloniales. Editorial UC. Acessado em 26/09/2018 e disponível em:

http://seminariodefeminismonuestroamericano.blogspot.com.br/2015/04/pdf-tejiendo-de-otromodo-feminismo.html.

NASCIMENTO, ABDIAS (2017). O genocídio do povo brasileiro: processo de um genocídio mascarado. I reimpressão da 2. Ed. - São Paulo: Perspectiva.

PAIXÃO, M. (2006). Manifesto anti-racista: idéias em prol de uma utopia chamada Brasil. Rio de janeiro: DP\&A; LLP/UERJ. 
PARTEMAN, Carole (1993). O contrato sexual. Tradução: Marta Avancini. Editora; Paz e Terra.

SAFFIOTI, Heleieth (2013). A mulher na sociedade de classes. São Paulo: Expressão Popular, 3. Ed., 528p.

(1992). Rearticulando gênero e classe social. IN: COSTA, Albertina de Oliveira e BRUSCHINI, Cristina. Uma Questão de gênero. 183-215. Rio de Janeiro: Editora Rosa dos Tempos e São Paulo. Fundação Carlos Chagas.

(2004). Descobertas da área das perfumarias. IN: Gênero, patriarcado, violência. São Paulo: Editora Fundação Perseu Abramo, 39-68.

(2016) Patriarcado-capitalismo a partir da Ideologia Alemã. Link: http://lavrapalavra.com/2016/02/12/patriarcado-capitalismo-heleieth-saffioti-a-partir-de-aideologia-alema/. Acesso em 17/07/2017

SINGER, Paul (1977(. Economia política do Trabalho. São Paulo: Hucitec, p. 99-197.

TELLES, Lorena Féres da Silva (2013). Libertas entre sobrados: mulheres negras e o trabalho doméstico em são Paulo (18880-1920). São Paulo: Alameda.

WIKIPÉDIA. Conceito de Racismo Institucional. Disponível em: https://pt.wikipedia.org/wiki/Racismo institucional. Acesso em 17/07/2017. Acessado em 26/09/2018. 